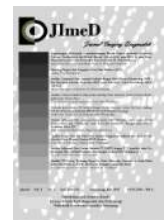

Jurnal Imejing Diagnostik (JImeD) 7 (2021) 41-47

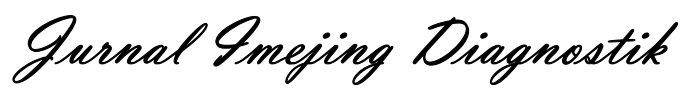

e-ISSN 2621-7457, p-ISSN 2356-301X

\title{
Analisis Variasi Flip Angle Terhadap Informasi Citra Anatomi Pada Sekuen 3D TOF MRA Brain Dengan MRI 3 Tesla
}

\author{
Fatimah $^{1}$, Dwi Rochmayanti ${ }^{2}$, Fina Kristianti ${ }^{3}$ \\ 1, ${ }^{2}$ Poltekkes Kemenkes Semarang, Indonesia \\ ${ }^{3}$ Emergency Hospital (RSDC) Kemayoran Athlete Village, Indonesia \\ Corresponding author: Fatimah \\ Email : fatimah_yunaeza@yahoo.com
}

Received: January $27^{\text {th }}, 2021$; Revised: January $31^{\text {st }}, 2021$; Accepted: February $1^{\text {st }}, 2021$

\begin{abstract}
Background : Magnetic Resonance Angiography is a diagnostic imaging method that can display images of blood vessels. MRA imaging on MRI 3 Tesla provides high spatial resolution making blood vessel contrast increased so that the intracranial vessels are clearer. The efficient technique that does not use contrast media in MRA is Time of Flight. 3D TOF imaging is good for visualizing intracranial vessels. In this method the appropriate flip angle will produce a hyperintense picture of the blood vessels. This study aims to determine the effect of flip angle on anatomical image information on 3D TOF MRA Brain.

Methods : This type of research is a quantitative experimental approach, conducted in February 2020 in Pertamina Central Hospital, South Jakarta. Research by conducting flip angle variations of $15^{\circ}, 20^{\circ}$, $25^{\circ}, 30^{\circ}$ in the $3 \mathrm{D}$ TOF sequence of the Brain against 10 volunteers. Criteria for volunteers are healthy people aged 18-25 years. The results of the images were assessed by 3 respondent, including Internal Carotid Artery, Vertebral Artery, Basilar Artery, Anterior Cerebral Artery, Posterior Cerebral Artery, Middle Cerebral Artery, Anterior Communicating Artery, Posterior Communicating Artery. Then the Kappa test was carried out followed by the Friedman test to find the highest mean rank and comparison of flip angle in anatomical information of 3D TOF MRA Brain.

Results : The results showed that there was an effect of changes in the values of the flip angle to the anatomical information on 3D TOF MRA Brain with $p<0,05$. The optimal Flip angle value is obtained based on the highest mean rank value which is flip angle $25^{\circ}$ with a value of 3,22 . The higher the value of flip angle, the greater the signal and contrast, but many slow flowing blood vessels will hypointens. Conclussion : There are difference in anatomical image information of 3D TOF sequence among 4 variation flip angle on examination MRA Brain. Flip angle $25^{\circ}$ is better than $15^{\circ}, 20^{\circ}$ and $30^{\circ}$ at anatomy information on 3D TOF sequences to show intracranial artery because it has a higher mean rank value.
\end{abstract}

Keywords : Flip Angle, 3D TOF MRA Brain, Anatomical Image Information, 3 Tesla.

\section{Pendahuluan}

Magnetic Resonance Angiography merupakan metode pencitraan diagnostik yang dapat menampilkan gambaran pembuluh darah menggunakan modalitas MRI. Pencitraan MRA pada MRI 3 Tesla mampu memberikan resolusi spasial tinggi membuat kontras pembuluh darah meningkat sehingga dapat memvisualisasikan pembuluh darah intracranial dengan lebih jelas (Born et al., 2003).

Teknik MRA menggunakan variasi dari akuisisi gradient echo untuk menghasilkan sinyal tinggi dalam flowing vessel. Kontras vascular dimaksimalkan dengan meningkatkan sinyal dari flowing spin dan menekan sinyal dari spin stasioner dalam suatu jaringan. Pemeriksaan MRA dapat menggunakan beberapa teknik yaitu, Digital Substraction on MR Angiography (DS-MRA), Time of Flight (TOF) MRA, Phase Contrast MRA (PCMRA), dan Contrast Enchancement MRA (CEMRA) (Westbrook, 2011).

Salah satu teknik yang efisien waktu untuk mendapatkan gambaran vascular dan tidak menggunakan media kontras dalam pemeriksaan MRA yaitu Time of Flight (TOF). Pada TOF, sumber utama sinyal yang dihasilkan bergantung pada intensitas sinyal dari flowing spin yang masuk 
ke dalam volume pencitraan yang menghasilkan sinyal hyperintense. Pembuluh darah akan menghasilkan high signal dan jaringan stasioner menghasilkan low signal (Dale, 2015).

TOF MRA dapat diakuisi menggunakan teknik 2D dan 3D. Pencitraan 3D TOF baik untuk memvisualisasikan struktur pembuluh darah yang kecil dengan aliran darah berkecepatan tinggi seperti pembuluh intracranial (Schneider, 2005). 3D TOF menghasilkan kontras pembuluh darah yang optimal dan merupakan teknik yang paling sensitive dan akurat dalam memperlihatkan anatomi dari intracanial (Kapsalaki, Rountas, and Fountas, 2012). Pada metode ini penggunaan flip angle yang sesuai akan membuat TOF menghasilkan gambaran pembuluh darah yang hyperintense. Flip angleyang optimal akan menghasilkan suppression yang lebih baik pada jaringan stasioner. Pengaruh flip angle yang tidak tepat akan menghasilkan enhancement yang kurang baik pada aliran pembuluh darah yang mungkin akan mengganggu gambaran terutama jika terdapat patologis (Schneider, 2005).

Menurut Morelli et al, (2013) dan Atkinson, et al (1994) flip angle digunakan untuk mengontrol saturasi antara darah yang mengalir dan jaringan stasioner. Secara umum, flip angle yang lebih tinggi menghasilkan derajat kejenuhan pada background yang lebih besar. Semakin tinggi flip angle pada irisan yang lebih dalam berarti jaringan stasioner di sana akan menjadi lebih jenuh dan semakin ditekan sehingga membuat pembuluh darah akan tampak lebih mencolok, sedangkan pada flip angle yang rendah akan menghasilkan sebaliknya.

Menurut literatur kepustakaan yang ada flip angle yang digunakan pada 3D TOF MRA yaitu $10^{\circ}$ - $30^{\circ}$ (Stuelke, 2019), $15^{\circ}-20^{\circ}$ (Schneider, 2005), $20^{\circ}-30^{\circ}$ (Westbrook, 2014) dan $20^{\circ}-40^{\circ}$ (Weishaupt \& Marincek, 2006), sedangkan peneliti menjumpai pengaturan nilai flip angle di Rumah Sakit Pusat Pertamina menggunakan nilai flip angle $18^{\circ}$. Tujuan penelitian ini untuk mengetahui pengaruh variasi nilai Flip Angle terhadap informasi citra anatomi pada sekuen 3D TOF MRA Brain dan nilai variasi yang lebih optimal dalam menampilkan informasi citra anatomi pada sekuen 3D TOF MRA Brain dengan modalitas MRI 3 Tesla.

\section{Metode}

Jenis penelitian yaitu penelitian kuantitatif dengan pendekatan eksperimental, dilakukan pada bulan Februari 2020 di Instalasi Radiologi Rumah Sakit Pusat Pertamina, Jakarta Selatan. Responden yang melakukan penilaian informasi citra anatomi yaitu berjumlah tiga orang dokter spesialis radiologi.

Sampel pada penelitian ini sebanyak 10 orang sehat sebagai volunteer dengan kriteria inklusi berusia $18-25$ tahun dan bersedia menjadi sampel penelitian.

Modalitas MRI yang digunakan adalah merk Philips Ingenia 3 Tesla. Parameter pada sekuen 3D TOF MRA Brain ini meliputi TR $=23 \mathrm{~ms}, \mathrm{TE}=3,5$ $\mathrm{ms}$, Matrix $=288 \times 180$, Bandwidth $=31 \mathrm{KHz}, \mathrm{FOV}$ $=200 \mathrm{~mm}$, Slice Thickness $=2 \mathrm{~mm}$ dan NEX $=1$. Kemudian citra yang dihasilkan diberikan penilaian informasi citra anatomi oleh responden dengan memberikan skor pada gambaran anatomi arteri intracranial, skor (1) dengan arti tidak jelas, apabila pembuluh darah pada arteri tidak terlihat atau gelap, batas dinding pembuluh darah tidak tegas, kabur dan sulit diamati. Skor (2) dengan arti jelas, apabila pembuluh darah pada arteri terlihat namun tidak tegas dan terang batas-batasnya dan kurang mudah diamati oleh responden. Skor (3) dengan arti sangat jelas, apabila pembuluh darah pada arteri terang dengan batas-batas yang pasti dan mudah diamati oleh responden.

Data kemudian diolah menggunakan SPSS 16.0 dengan uji statistic. Uji statistic pertama adalah Cohen's Kappa untuk mengetahui tingkat persamaan persepsi antar responden. Kemudian dilanjutkan dengan analisis uji statistik Friedman untuk melihat apakah ada perbedaan dan untuk melihat nilai yang baik dari interpretasi nilai mean rank. Nilai mean rank tertinggi akan dijadikan nilai flip angle yang optimal pada 3D TOF MRA Brain.

\section{Hasil dan Pembahasan}

Penelitian mengenai analisis variasi flip angle terhadap informasi citra anatomi pada sekuen 3D TOF MRA Brain dengan MRI 3 Tesla telah dilakukan pada 10 orang volunteer sehat yang terdiri dari 3 orang laki-laki dan 7 orang perempuan, usia volunteer berada pada rentang 19-21 tahun dengan perincian 5 orang berusia 19 tahun, 4 orang berusia 20 tahun dan 1 orang berusia 21 tahun. Pada tiap volunteer dilakukan pemeriksaan MRA Brain dengan sekuen 3D TOF menggunakan variasi flip angle yaitu $15^{\circ}, 20^{\circ}, 25^{\circ}$ dan $30^{\circ}$.

Hasil citra 3D TOF MRA Brain kemudian dilabeli dengan kode A sebagai flip angle $15^{\circ}$, kode $\mathrm{B}$ sebagai flip angle $20^{\circ}$, kode $\mathrm{C}$ sebagai flip angle $25^{\circ}$ dan kode $\mathrm{D}$ sebagai

flip angle $30^{\circ}$.

Pengalaman ketrampilan membaca MRI tiap responden sebagai berikut, responden pertama memiliki pengalaman 15 tahun, responden kedua memiliki pengalaman 11 tahun dan responden 3 
memiliki pengalaman 12 tahun. Kemudian responden akan memberikan penilaian informasi citra anatomi pada citra 3D TOF MRA Brain. Anatomi yang dinilai dalam penelitian ini yaitu Internal Carotid Artery (ICA), Vertebral Artery (VA), Basillary Artery (BA), Anterior Cerebral Artery (ACA), Posterior Cerebral Artery (PCA), Middle Cerebral Artery (MCA), Anterior Communicating Artery, Posterior Communicating Artery, dengan skala penilaian dibagi menjadi 3 yaitu skor penilaian $1=$ tidak jelas, $2=$ jelas, dan 3 $=$ sangat jelas.

Adapun hasil citra 3D TOF MRA Brain salah satu sampel adalah sebagai berikut :

Gambaran arteri intracranial terlihat dari anterior view pada gambar 1, sagittal view pada gambar 2 dan sagittal oblique view pada gambar 3 dengan masing-masing citra menggunakan 4 variasi flip angle yaitu flip angle $15^{\circ}$ pada Gambar A, flip angle $20^{\circ}$ pada Gambar B, flip angle $25^{\circ}$ pada Gambar C, flip angle $30^{\circ}$ pada Gambar D.

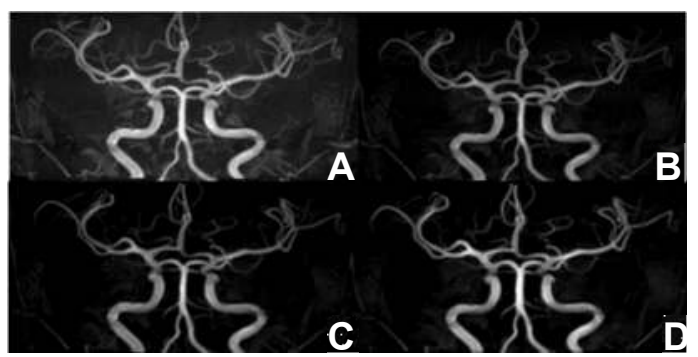

Gambar 1. Hasil citra 3D TOF MRA Brain anterior view

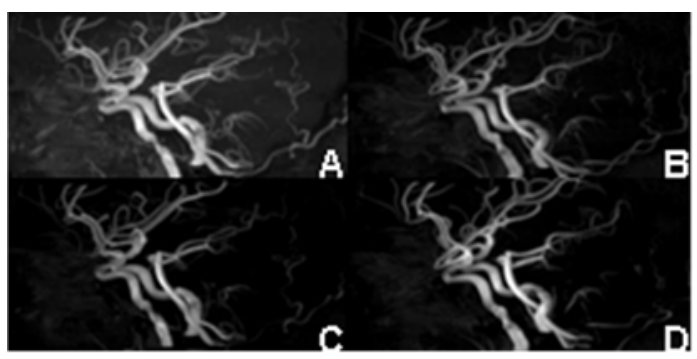

Gambar 2. Hasil citra 3D TOF MRA Brain sagital view

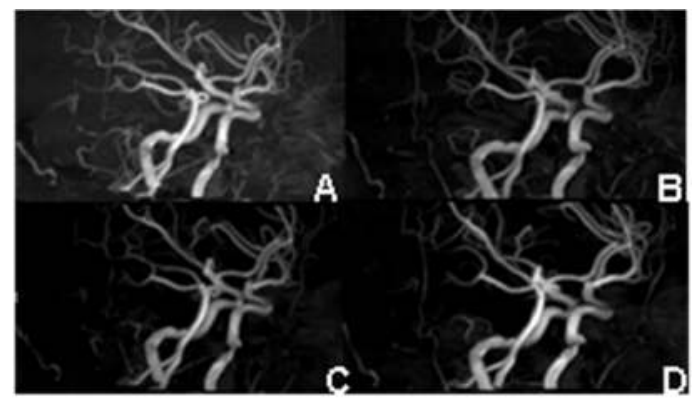

Gambar 3. Hasil citra 3D TOF MRA Brain sagital oblique view

Pengujian statistika yang pertama dilakukan ${ }_{\mathrm{a}}$ adalah Uji Cohen's Kappa yang bertujuan untuk mengetahui tingkat kesepakatan atau kesamaan pesepsi antar responden dalam pemberian skor penilaian citra. Hasil pengujian Cohen's Kappa terhadap ketiga responden dalam penelitian ini yaitu sebagai berikut :

Tabel 1. Hasil Uji Cohen's Kappa pada Responden 1 dan 2

\begin{tabular}{lll}
\hline Value Kappa & $\boldsymbol{p}$ Value & Makna \\
\hline 0,692 & $\mathrm{p}<\alpha$ & Kesepakatan kuat \\
\hline
\end{tabular}

Tabel 2. Hasil Uji Cohen's Kappa pada Responden 1 dan 3

\begin{tabular}{lll}
\hline Value Kappa & p Value & Makna \\
\hline 0,845 & $\mathrm{p}<\alpha$ & Kesepakatan kuat \\
\hline
\end{tabular}

Tabel 3. Hasil Uji Cohen's Kappa pada Responden 2 dan 3

\begin{tabular}{lll}
\hline Value Kappa & $\boldsymbol{p}$ Value & Makna \\
\hline 0,737 & $\mathrm{p}<\alpha$ & Kesepakatan kuat \\
\hline
\end{tabular}

Berdasarkan ketiga tabel, semua hasil perhitungan statistika Uji Cohen's Kappa yang diperoleh terdapat pada rentang kesepakatan yang kuat, sehingga peneliti dapat menggunakan data penilaian kejelasan informasi citra anatomi dari salah satu responden. Dalam hal ini peneliti menggunakan data yang diperoleh dari responden pertama yang memiliki pengalaman paling lama dalam membaca MRI.

Selanjutnya karena data informasi citra yang didapatkan berupa data ordinal sehingga data berdistribusi tidak normal, maka digunakan uji Friedman untuk mengetahui perbedaan informasi citra terhadap variasi flip angle pada 3D TOF MRA Brain.

\begin{tabular}{cccc}
\multicolumn{3}{c}{ Tabel 4. Hasil Uji Friedman Variasi Flip } & \\
$\frac{\text { Angle }}{\text { Variasi Flip }}$ & Mean Rank & Asymp. Sig & Makna \\
& & & \\
\hline Angle & & & \\
\hline & & & \\
$25^{\circ}$ & 1,78 & & \\
$20^{\circ}$ & 2,74 & $<0,000$ & \\
$30^{\circ}$ & 3,22 & & \\
\hline
\end{tabular}

Berdasarkan tabel 4. terlihat nilai asymp. signifikansi dari uji friedman variasi flip angle pada informasi citra anatomi secara keseluruhan adalah $\mathrm{p}<0,05$ yang menandakan bahwa terdapat perbedaan rata-rata pada masing-masing variasi nilai flip angle.

Kemudian dilanjutkan dengan uji friedman tiap bagian anatomi arteri intracranial pada citra 3D TOF MRA Brain. Uji ini dilakukan dengan tujuan untuk mengetahui nilai flip angle mana yang paling baik dalam menampakkan citra masing-masing bagian arteri intracranial, dan hasilnya sebagai berikut :

Pada Internal Carotid Artery, signifikansi variasi flip angle pada anatomi Internal Carotid Artery 
yaitu $\mathrm{p}=0,005$, yang artinya terdapat perbedaan $(\mathrm{p}<0,05)$ antara tiap variasi flip angle dengan Internal Carotid Artery.

b. Pada Vertebral Artery, signifikansi variasi flip angle pada anatomi Vertebral Artery yaitu $p=0,000$, yang artinya terdapat perbedaan $(\mathrm{p}<0,05)$ antara tiap variasi flip angle dengan Vertebral Artery.

c. Pada Basilar Artery, signifikansi variasi flip angle pada anatomi Basilar Artery yaitu $\mathrm{p}=0,001$, yang artinya terdapat perbedaan $(\mathrm{p}<0,05)$ antara tiap variasi flip angle dengan Basilar Artery.

d. Pada Anterior Cerebral Artery, signifikansi variasi flip angle pada anatomi Anterior Cerebral Artery, yaitu $\mathrm{p}=0,001$, yang artinya terdapat perbedaan $(\mathrm{p}<0,05)$ antara tiap flip angle variasi dengan Anterior Cerebral Artery.

e. Pada Posterior Cerebral Artery, signifikansi variasi flip angle pada anatomi Posterior Cerebral Artery yaitu $\mathrm{p}=0,008$, yang artinya terdapat perbedaan $(\mathrm{p}<0,05)$ antara tiap variasi flip angle dengan Posterior Cerebral Artery.

f. Pada Middle Cerebral Artery, signifikansi variasi flip angle pada anatomi Middle Cerebral Artery yaitu $\mathrm{p}=0,000$, yang artinya terdapat perbedaan $(\mathrm{p}<0,05)$ antara tiap variasi flip angle dengan Middle Cerebral Artery.

g. Pada Anterior Communicating Artery, signifikansi variasi flip angle pada anatomi Anterior Communicating Artery yaitu $\mathrm{p}=0,187$, yang artinya tidak terdapat perbedaan $(\mathrm{p}>0,05)$ antara tiap variasi flip angle dengan Anterior Communicating Artery.

h. Pada Posterior Communicating Artery, signifikansi variasi flip angle pada anatomi Posterior Communicating Artery yaitu $\mathrm{p}=0,008$, yang artinya terdapat perbedaan $(\mathrm{p}<0,05)$ antara tiap variasi flip angle dengan Posterior Communicating Artery.

Setelah itu untuk mengetahui nilai flip angle yang optimal dalam memvisualisasikan informasi citra anatomi pada 3D TOF MRA Brain, peneliti menggunakan data informasi citra anatomi hasil penilaian responden yang dapat dilihat pada hasil uji Friedman pada tabel 4. yang menunjukkan bahwa flip angle $15^{\circ}$ dengan nilai mean rank 1,78, flip angle $20^{\circ}$ dengan nilai mean rank 2,74, flip angle $25^{\circ}$ memiliki nilai mean rank yang lebih tinggi dibandingkan dengan yang lain yaitu 3,22 , dan flip angle $30^{\circ}$ memiliki nilai mean rank 2,27 , sehingga dapat disimpulkan bahwa flip angle $25^{\circ}$ memiliki nilai mean rank yang tertinggi yang artinya flip angle $25^{\circ}$ merupakan flip angle yang mampu memberikan informasi citra anatomi pada 3D TOF MRA Brain secara keseluruhan paling baik diantara variasi lain yang diuji.

\section{Pengaruh variasi nilai Flip Angle terhadap informasi citra anatomi pada sekuen 3D TOF MRA Brain dengan modalitas MRI 3 Tesla}

Hasil data penelitian diolah menggunakan uji statistika friedman dimana uji statistika friedman tersebut dapat digunakan sebagai dasar untuk menentukan pengaruh variasi flip angle terhadap informasi citra anatomi yang sudah ditentukan sebelumnya. Untuk mengetahui pengaruh tersebut adalah dengan dilakukannya uji friedman terhadap seluruh anatomi yang sudah ditentukan dan selanjutnya dijabarkan ke masing-masing anatomi. Kemudian diperoleh hasil Asymp.Sig lebih kecil dari $0,05(\mathrm{p}<0,05)$ yang artinya ada perbedaan dari perubahan variasi flip angle yang dapat juga diartikan bahwa perubahan variasi flip angle berpengaruh terhadap informasi citra anatomi yang dibaca oleh dokter radiolog sehingga dapat disimpulkan Ha diterima.

Menurut Schneider (2005) pencitraan 3D TOF baik untuk memvisualisasikan struktur pembuluh darah yang kecil dengan aliran darah berkecepatan tinggi seperti pembuluh intracranial. 3D TOF MRA menggunakan incoherent GRE yang dikombinasikan dengan gradient moment rephasing yang dapat membuat flow enhance. Pada metode ini penggunaan flip angle dan TR yang sesuai akan membuat TOF menghasilkan gambaran pembuluh darah yang hyperintense (Kapsalaki et al., 2012). Flip angle dan TR digunakan agar nukelus stasioner tersaturasi,,sementara efek inflow fully magnetization dari flowing nucleus dikatakan fresh spin atau akan menghasilkan high signal pada pembuluh darah. Dengan flip angle dan TR yang tepat TOF MRA akan menghasilkan pembuluh darah yang terang (Westbrook, 2011).

Flip angle yang optimal pada 3D TOF MRA Brain akan menghasilkan penekanan yang lebih baik pada jaringan stasioner sehingga hypointense (Schneider, 2005). Menurut peneliti flip angle yang tepat akan memberikan derajat sudut balik yang baik untuk recovery. Dengan flip angle yang kecil maka semakin cepat suatu nucleus untuk recovery dan menghasilkan sinyal. Setiap kenaikan nilai flip angle akan membuat sudut balik nucleus untuk recovery semakin lama sehingga akan menghasilkan suppresion atau penekanan yang lebih banyak pada jaringan stationer yang membuat gambaran menjadi hypointense dan sinyal yang dihasilkan juga lebih besar pada pembuluh darah. Oleh karena itu, ketajaman atau batas tegas antara pembuluh darah dengan organ sekitar akan terlihat baik karena organ sekitar akan akan mengalami suppression yang lebih optimal sehingga menjadi hypointense dan pembuluh darah semakin 
hyperintense. Pengaruh flip angle yang tidak tepat akan menghasilkan enhancement yang kurang baik pada aliran pembuluh darah yang mungkin akan mengganggu gambaran terutama jika terdapat patologis.

Berdasarkan gambar 1, 2 dan 3 Flip angle yang lebih tinggi menghasilkan sinyal dan kontras yang lebih besar pada point of entry dari flowing blood daripada flip angle yang lebih rendah, namun penetrasi kedalaman yang dihasilkan rendah. Flip Angle yang besar akan membuat progresif kehilangan sinyal karena saturasi lebih terlihat. Sebaliknya, dengan flip angle yang lebih rendah, sinyal pembuluh darah dan kontras jauh lebih sedikit namun memiliki penekanan kedalaman yang lebih baik. Terlihat jelas pada penelitian ini sangat berbeda sekali kontras dan batas tegas antara pembuluh darah dengan organ sekitar antara flip angle $15^{\circ}, 20^{\circ}, 25^{\circ}$ dan $30^{\circ}$. Flip angle $30^{\circ}$ memiliki kontras dan batas tegas yang paling baik, namun banyak pembuluh darah dengan aliran lambat yang ikut mengalami suppression sehingga menjadi hypointense, sedangkan pada flip angle $15^{\circ}$ kontras dan batas tegas yang dihasilkan pada citra 3D TOF MRA Brain kurang jelas, namun karena penetrasi kedalamannya baik maka dapat menampilkan pembuluh darah dengan aliran yang lambat terlihat hyperintens. Penelitian variasi flip angle pada 3D TOF MRA Brain ini dilakukan pada MRI 3 Tesla. Pencitraan MRA pada MRI 3 Tesla ini mampu memberikan resolusi spasial tinggi, membuat kontras pembuluh darah meningkat dan penekanan lemak yang lebih baik sehingga dapat memvisualisasikan pembuluh darah intracranial dengan lebih jelas (Born et al., 2003). Menurut Runge (2018) pencitraan menggunakan MRI 3 Tesla memberikan peningkatan kualitas citra yang lebih besar pada 3D TOF MRA. Hal ini disebabkan oleh berkurangnya sinyal jaringan stasioner dan penetrasi kedalaman yang lebih baik. Apabila dibandingkan dengan MRI 3 Tesla, pencitraan MRA pada MRI 1,5 Tesla masih memiliki resolusi spasial terbatas yang membuat SNR lebih rendah dan secara simultan akan menurunkan kualitas citra, selain itu hasil citra pada segmen perifer dari arteri cerebral utama yang merupakan potensi penyebab infark atau lokasi potensial aneurisma intracranial seringkali tidak terlihat jelas (Born et al., 2003). Menurut Nowinski et al (2013), untuk pemeriksaan pembuluh darah arteri menggunakan MRI 3 Tesla merupakan yang terbaik dibandingkan dengan 1,5 Tesla dan 7 Tesla.
Nilai Flip Angle yang mampu menampilkan informasi citra anatomi lebih optimal pada sekuen 3D TOF MRA Brain dengan modalitas MRI 3 Tesla

Pada 3D TOF MRA, ada banyak faktor yang mempengaruhi intensitas sinyal vascular, seperti kecepatan dan arah aliran darah, waktu relaksasi T1 dari aliran darah, dan parameter pencitraan (TR, TE, flip angle, dan slab thickness). Parameter TR, TE dan flip angle merupakan faktor yang sangat penting untuk kontras vascular yang baik. Salah satu kelemahan utama dari 3D TOF MRA adalah hilangnya sinyal karena efek saturasi, khususnya pada pembuluh darah dengan aliran darah yang lambat. Pada 3D TOF MRA Brain, kontras antara aliran dan jaringan stasioner bergantung pada TR dan flip angle. TR dan flip angle akan mempengaruhi Signal to Noise Ratio, Contrast to Noise Ratio dan juga scan time. TR yang biasanya digunakan dalam 3D TOF MRA, yaitu 20-50 ms (Westbrook, 2011) sedangkan flip Angle yang biasa digunakan yaitu $10^{\circ}-30^{\circ}$ (Stuelke, 2019), $15^{\circ}-20^{\circ}$ (Schneider, 2005), $20^{\circ}-30^{\circ}$ (Westbrook, 2014), $20^{\circ}$ $-35^{\circ}$ (Choi et al, 2011) dan $20^{\circ}-40^{\circ}$ (Weishaupt, 2006).

Dalam penelitian ini peneliti menggunakan flip angle $15^{\circ}, 20^{\circ}, 25^{\circ}$ dan $30^{\circ}$ yang bertujuan untuk melihat flip angle mana yang lebih optimal dalam menampilkan informasi citra anatomi. Penelitian ini tidak menggunakan flip angle $18^{\circ}$ yang merupakan parameter yang biasa digunakan pada Rumah Sakit Pusat Pertamina dikarenakan nantinya flip angle tersebut akan diasumsikan menjadi flip angle $20^{\circ}$ yang memiliki hasil citra yang serupa dengan flip angle $18^{\circ}$ dimana dalam pengamatan peneliti kontras dan batas-batas antara pembuluh darah dengan organ sekitar yang dihasilkan tampak sama, pada bagian pembuluh darah kecil dengan kecepatan aliran tinggi nampak hyperintense dan tidak banyak pembuluh darah dengan kecepatan aliran lambat yang berubah menjadi hypointense, selain itu juga persamaan keduanya terlihat jelas pada pada anterior cerebral artey, posterior cerebral artery dan basilar artey dimana enhancement yang dihasilkan cukup baik.

Berdasarkan data penelitian yang dihasilkan, nilai flip angle yang optimal dapat dilihat melalui hasil mean rank tertinggi pada hasil uji friedman pada tabel 4. Pada tabel 4. hasil uji friedman keempat variasi, flip angle $25^{\circ}$ merupakan flip angle yang memiliki nilai mean rank tertinggi yaitu sebesar 3,22. Pada gambar 1, 2 dan 3 dari citra 3D TOF MRA Brain volunteer normal menunjukkan perbedaan peningkatan vascular yang terjadi pada variasi flip angle dari $15^{\circ}, 20^{\circ}, 25^{\circ}$ hingga $30^{\circ}$. Menurut peneliti flip angle $25^{\circ}$ memiliki saturasi 
yang sangat baik dari nucleus stationer sehingga menghasilkan kontras yang tinggi dengan batasbatas tegas antara pembuluh darah dengan organ sekitar, selain itu juga pembuluh darah dengan aliran lambat tidak banyak yang mengalami suppression dan enhancement tetap optimal, yang artinya tidak banyak informasi citra yang hilang. Flip angle $25^{\circ}$ mampu menampilkan informasi citra anatomi paling baik dikarenakan mampu memberikan derajat sudut balik yang baik untuk recovery sehingga akan menghasilkan suppression atau penekanan yang optimal pada jaringan stationer dan sinyal yang dihasilkan juga lebih besar pada pembuluh darah dengan aliran yang cepat.

Berdasarkan tabel 4 . hasil uji friedman peranatomi pada tiap variasi menunjukkan anatomi Internal Carotid Artery, Vertebral Artery, Basillar Artery, Anterior Cerebral Artery, Posterior Cerebral Artery dan Anterior Communicating Artery menghasilkan mean rank tertinggi pada flip angle $25^{\circ}$, sedangkan pada Middle Cerebral Artery mean rank tertinggi pada flip angle $20^{\circ}$ dan $25^{\circ}$, dan pada Posterior Communicating Artery mean rank tertinggi pada flip angle $20^{\circ}$. Menurut Ghazali (2003) Middle Cerebral Artery memiliki tingkat sensitifitas hingga $100 \%$ pada 3D TOF MRA Brain, dan pada penelitian ini kontras dan batas tegas dari Middle Cerebral Artery terlihat lebih jelas pada flip angle $20^{\circ}$ dan $25^{\circ}$, Middle Cerebral Artery merupakan cabang dari Internal Carotid Artery yang paling besar sehingga efek saturasi pada pembuluh darah ini akan baik pada flip angle yamon, optimal. Sedangkan Posterior Communicating Artery memiliki tingkat sensitifitas yang rend karena efek saturasi pada pembuluh darah dengan aliran lambat. Flip angle $20^{\circ}$ mampu menampilkan Posterior Communicating Artery dengan kontrăs dan batas tegas yang paling bagus karena penetrasi kedalamannya baik sehingga dapat memperlihatkan pembuluh darah tersebut yang merupakan pembuluh darah aliran lambat menjadi terlihat lebỉhale, jelas.

\section{Simpulan}

Berdasarkan hasil penelitian dan pembahasan dapat disimpulkan bahwa Perubahan nilai flip angkeaps berpengaruh terhadap informasi citra anatomi pada sekuen 3D TOF MRA Brain pada MRI 3 Tesla. Kesimpulan tersebut diperoleh dari hasil uji friedman yang menunjukkan Asymp Sig 0,000 ataulebih kecil dari $0,05(\mathrm{p}<0,05)$ yang artinya terdapat perbedaan penggunaan variasi flip angle terhadap informasi citra anatomi. Dengan adanya nilai perbedaan tersebut perubahan nilai flip angle berpengaruh terhadap informasi citra anatomi pada sekuen 3D TOF MRA Brain dengan modalitas MRI 3 Tesla.

Semakin tinggi nilai flip angle yang digunakan maka sinyal dan kontras yang dihasilkan semakin besar, dan suppression pada jaringan stationer akan semakin optimal, akan tetapi akan membuat pembuluh darah dengan aliran lambat mengalami suppression sehingga akan nampak hypointens.

Hasil uji mean rank friedman menunjukkan nilai flip angle yang mampu menampilkan informasi citra anatomi lebih optimal pada sekuen 3D TOF MRA Brain dengan modalitas MRI 3 Tesla yaitu flip angle $25^{\circ}$ dengan nilai mean rank 3,22. Nilai flip angle $25^{\circ}$ mampu menghasilkan informasi citra anatomi dari Internal Carotid Artery (ICA), Vertebral Artery (VA), Basillar Artery (BA), Anterior Cerebral Artery (ACA), Posterior Cerebral Artery (PCA), Middle Cerebral Artery (MCA), Anterior Communicating Artery, Posterior Communicating Artery menjadi lebih jelas dengan batas-batas tegas antara pembuluh darah dan organ sekitar.

\section{Daftar Pustaka}

kinson, D., Brant-Zawadzki, M., Gillan, G., Purdy, D., \& Laub, G. 1994. Improved MR angiography: Magnetization transfer suppression with variable flip angle excitation and increased resolution. Radiology, 190(3),

https://doi.org/10.1148/radiology.190.3.8115646 890-894.

n, M., Simon, B., Tschampa, H. J., Krautmacher, C., Urbach, H., Textor,

J., \& Schild, H. H. 2003. Radiology Angiography: Comparison of 3 . 0-T Imaging and 1 . 5-T Imaging Initial Experience 1. Radiology, (229), 913-920.

i, J. W., Roh, H. G., Moon, W.-J., Chun, Y. Il, \& Kang, C. H. 2011.

timization of MR Parameters of 3D TOF-MRA for Various Intracranial Stents at 3.0T MRI. Neurointervention, 6(2), 71. https://doi.org/10.5469/neuroint.2011.6.2.71

, B. M., Brown, M. A., \& Semelka, R. C. 2015. MRI Basic Principles and Applications (Fifth Edit). United Kingdom: John Wiley \& Sons, Ltd.

Ghazali, R. M., \& Shuhaib, I. lutfi. 2003. Comparison Between 3d Tof Magnetic Resonance Angiography And Intraarterial Digital Subtraction. 10(1), 37-42.

salaki, E. Z., Rountas, C. D., \& Fountas, K. N. 2012. The role of 3 Tesla MRA in the detection of intracranial aneurysms. International Journal of Vascular Medicine, 2012. https://doi.org/10.1155/2012/792834

relli, J. N., Gerdes, C. M., Schmitt, P., Ai, T., Saettele, M. R., Runge, V. M., \& Attenberger, U. I. 2013. Technical considerations in MR angiography: An image-based guide. Journal of Magnetic Resonance Imaging, 37(6), 1326-1341. https://doi.org/10.1002/jmri.24174 
Runge, V. M., Nitz, W. R., \& Heverhagen, J. T. 2018. The Physics of Clinical MR Taught Through Images (Fouth Edit). New York: Thieme Medical Publishers, ,nc.

Schneider, G., Prince, M. R., Meaney, J. F. M., \& Ho, V. B. (2005). Magnetic Resonance Angiography. Technique, Indications and Practical Applications. New York: Springer Milan Berlin Heidelberg.

Stuelke S. 2019. A database of MRI and MRA protocols. MRprotocols.com (diakses pada 13 Januari 2020)

Weishaupt, D., \& Marincek, B. 2006. How Does MRI Work? Second Edition.

Germany: Springer.

Westbrook, C. 2014. Handbook of MRI Technique. Fourth. India: Wiley Blackwell Ltd.

Westbrook, C., Kaut Roth, C., \& Talbot, J. 2011. MRI in Practice $4^{\text {th }}$ Edition. USA: Wiley Blackwell Science Ltd 